\title{
Transient luminous event coordinated observations using FORMOSAT-2 satellite and Taiwan sprites campaign
}

\author{
Kang-Ming Peng ${ }^{1, *}$, Rue-Ron Hsu ${ }^{1}$, Han-Tzong $\mathrm{Su}^{1}$, Alfred Chen ${ }^{2}$, Jung-Kung Chou ${ }^{1}$, Shu-Chun Chang ${ }^{1}$, \\ Yen-Jung $\mathrm{Wu}^{1}$, Chien-Lun Hung ${ }^{3}$, I-Ching Yang ${ }^{4}$, and Sung-Hui Tsai ${ }^{5}$ \\ ${ }^{1}$ Department of Physics, National Cheng Kung University, Tainan City, Taiwan \\ ${ }^{2}$ Institute of Space and Plasma Sciences, National Cheng Kung University, Tainan City, Taiwan \\ ${ }^{3}$ Department of Communication Engineering, National Penghu University of Science and Technology, Penghu County, Taiwan \\ ${ }^{4}$ Department of Applied Science, National Taitung University, Taitung, Taiwan \\ ${ }^{5}$ Jincheng Junior High School, Kinmen, Taiwan
}

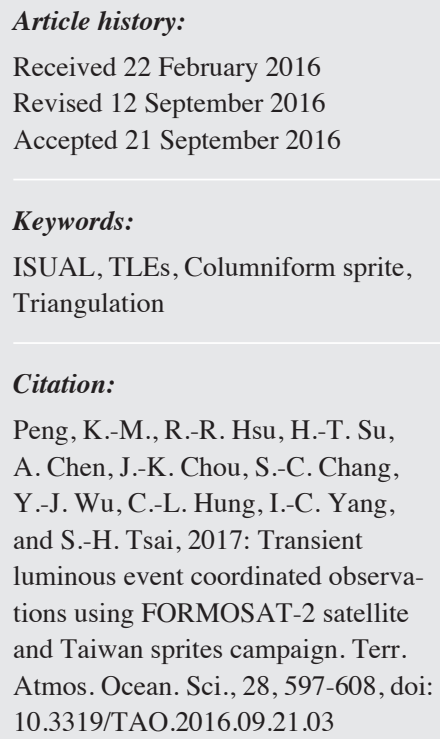

\begin{abstract}
The Imager of Sprites and Upper Atmospheric Lightning (ISUAL), on board the FORMOSAT-2 satellite launched in 2004, is the first instrument primarily dedicated to transient luminous event (TLE) surveys from space. The ISUAL TLE geolocation accuracy and detection efficiency are validated in this paper through two coordinated observation events using ISUAL and the Taiwan TLE ground campaign, the first coordinated space and ground observations. Due to the long distances between TLEs and the observation stations, triangulation required taking the Earth's curvature into account using spherical trigonometry. After a series of systematic triangulation procedures, the results indicate that the coordinated ISUAL and ground station geolation accuracy is less than $7 \mathrm{~km}$. Moreover, three columniform sprites were recorded at multiple sites during the ground campaign. The triangulation of individual elements shows that the map projection of columniform sprites is nearly circular, parallel and fan shaped. The aforementioned events demonstrate that the columniform sprite distribution patterns are diverse. The average base altitude of the columns is $72.4 \pm 2.4 \mathrm{~km}$, and the average terminal altitude is $82.3 \pm 1.8 \mathrm{~km}$. The sprite column width is estimated to be $<0.5 \mathrm{~km}$.
\end{abstract}

\section{INTRODUCTION}

Since Franz et al. $(1990)$ recorded the first sprite with a low light camera in 1989, numerous observations have been carried out from the ground (Fukunishi et al. 1996; Stenbaek-Nielsen et al. 2000; Pasko et al. 2002; Su et al. 2002, 2003; Hsu et al. 2003; Van der Velde et al. 2007; Chou et al. 2010; Huang et al. 2012; Yang et al. 2013, 2015), airplane (Sentman et al. 1995; Wescott et al. 1995), and space (Boeck et al. 1998; Kuo et al. 2005; Chen et al. 2008; Chang et al. 2010; Chou et al. 2010; Lee et al. 2010, 2012; Jehl et al. 2013). Those observations indicate that Transient Luminous Events (TLEs) can be categorized into sprites, halos, elves, blue jets and gigantic jets.

Some research groups launched multiple station obser-

\footnotetext{
* Corresponding author

E-mail:128011025@mail.ncku.edu.tw
}

vations to extract the exact location and altitude of TLEs. For instance, during the Sprite94 campaign, Sentman et al. (1995) yielded the first color imagery and triangulation measurement of sprites and blue jets using two aircraft. The sprite observations showed that the red main body of sprites ranges from $50-90 \mathrm{~km}$ in height and $5-30 \mathrm{~km}$ in width, which was sometimes accompanied with an extending downward faint bluish tendril. The accuracy of their measurements is about $2-3 \mathrm{~km}$. Lyons (1996) also employed optical images and the National Lightning Detection Network to retrieve the location and height of sprites above the U.S. High Plains. Although lacking coordinated observation for triangulation, they assumed that the sprites occurred directly above the +CG location and then calculated the height using the elevation angle. Their results showed that the average height of sprite tops were $77(\sigma=5.1) \mathrm{km}$, the average 
height of sprite bases were $50 \mathrm{~km}$, and a few sprites with tendrils extended to $31 \mathrm{~km}$. They also pointed out the height variation in sprite tops might be related to the variation in night time ionosphere $\mathrm{E}$ layer. However, it is not conclusive that the standard deviation of a sprite's height is comparable to the height variation of the night time ionosphere in their measurements. Wescott et al. (1998) reported on the triangulation of columniform sprites. The average terminal altitude of individual columns was $86.7 \mathrm{~km}$ and the bottom was $76.2 \mathrm{~km}$. The sprite columns were nearly vertical and less than $1 \mathrm{~km}$ in diameter. Some events were accompanied with faint diffuse tendrils extending above and below the sprite.

Hayakawa et al. (2004) located winter sprites in the Hokuriku area (Japan Sea side) using Japan Lightning Detection Network data and optical images. They found that the height distribution of sprites ranged from $50-90 \mathrm{~km}$, and most occurrences were within $70-75 \mathrm{~km}$. Due to the possible shift between parent lightning and sprite, sprite height uncertainty would be $\sim 10 \mathrm{~km}$. Stenbaek-Nielsen et al. (2010) combined multiple site observations with high speed camera (10000 frames per second) to analyze sprite onset altitude, finding the onset altitudes was $66-89 \mathrm{~km}$ for the initial downward streamer and $64-78 \mathrm{~km}$ for upward streamers.

By analyzing the images of columniform sprites recorded in a single site observation, Vadislavsky et al. (2009) found that the sprite columns were arranged in highly eccentric elliptical forms or in straight rows, suggesting that the columniform sprite elements are organized in spaced intervals on the circumference of a circle centered directly above, or with a little offset to, the parent lightning. They also used a quasi-electrostatic (QE) field model with a charge above the conducting surface to demonstrate that the observed diameter and view angle of the columnar arrangement was close to the conventional breakdown field line contour at the same altitude. Even though they utilized a simulation method to infer the spatial arrangement of columniform sprites, the real spatial distributions still needs to be verified through multiple site coordinated observations.

The Imager of Sprites and Upper Atmospheric Lightning (ISUAL), on board FORMOSAT-2 (FS-2) satellite launched in 2004, is the first instrument primarily dedicated to observing TLEs from space. The main reason of observing TLE from space is to avoid atmospheric attenuation and achieve a global survey. A coordinated observation using both ISUAL and ground observations is necessary to examine the ISUAL positioning accuracy and detection efficiency. Thus, TLE ground campaigns near Taiwan were executed during the last ten years to accomplish the coordinated observations with ISUAL.

We report on two events recorded by the ISUAL and Taiwan TLE ground campaign coordinated observations. Three columniform sprites were recorded from multiple sites during the ground campaign. The detailed sprite spatial distribution shows features different from those reported by Vadislavsky et al. (2009). The detailed TLE triangulation processes will also be presented. The ISUAL TLE geolocation accuracy and detection efficiency will also be discussed.

\section{INSTRUMENTATION}

The ISUAL (Imager of Sprites and Upper Atmospheric Lightning) objectives on board the Taiwanese FORMOSAT-2 (FS-2) satellite are to observe TLEs from space to avoid atmospheric attenuation and achieve a global survey. The FS-2 satellite was launched on 21 May 2004 with a polar sun synchronous orbit at $891 \mathrm{~km}$ altitude. ISUAL consists of three optical instruments: an intensified CCD imager (Imager) with 5 selectable filters and a $6^{\text {th }}$ blank, a six-channel spectrophotometer (SP), and a dual-color array photometer (AP). ISUAL is looking eastward to the horizon, perpendicular to the orbit plane. The Imager records a sequence of six frames (including the trigger frame) with a $30 \mathrm{~ms}$ interval between two successive frames, inclusive of a $29 \mathrm{~ms}$ exposure time, and the image size is $512 \times 128$ pixels $\left[20^{\circ}(\mathrm{H})\right.$ $\left.\times 5^{\circ}(\mathrm{V})\right]$. The SP shares the same field of view as the Imager and records the spectrum in a $10 \mathrm{kHz}$ sampling rate. The measurement bands are listed as follows: SP1 (150 - 290 $\mathrm{nm}$; FUV, $\mathrm{N}_{2}$ LBH band), SP2 [335 - $341.2 \mathrm{~nm}$, centered at $\left.337 \mathrm{~nm} ; 2 \mathrm{PN}_{2}(0,0)\right]$, SP3 [387.1 - $393.6 \mathrm{~nm}$, centered at 391 $\left.\mathrm{nm} ; 1 \mathrm{NN}_{2}{ }^{+}(0,0)\right]$, SP4 $\left(658.9-753.4 \mathrm{~nm} ; 1 \mathrm{PN}_{2}\right)$, SP5 (centered at $777.4 \mathrm{~nm} ; \mathrm{O}_{\mathrm{I}}$ emission in lightning), and SP6 (250 - $\left.390 \mathrm{~nm} ; 2 \mathrm{PN}_{2}\right)$. The AP field of view is $22^{\circ}(\mathrm{H}) \times 3.6^{\circ}$ (V) with sixteen vertical equally spaced channels, whereby it has a vertical resolving power, and the observation bands are $370-450$ and $530-650 \mathrm{~nm}$. The sampling rate is $20 \mathrm{kHz}$ at the initial $20 \mathrm{~ms}$ around triggering and then is $2 \mathrm{kHz}$ to the end of the measurement. Detailed information for the ISUAL payload can be found in Chern et al. (2003).

The regular ground observation campaign near Taiwan began in 2001. It was expanded to four remotely controlled optical stations in 2011. The four stations are located at Tainan (NCKU), Taitung (TT), Penghu (PH), and Kinmen $(\mathrm{KM})$, as shown in Fig. 1. The observation systems at each station are identical: including two low light monochrome cameras (WATEC 902H2 ULTIMATE CCD) with $12 \mathrm{~mm} /$ $\mathrm{f} 1.2$ lenses, except for the CCD in NCKU which is WATEC $100-\mathrm{N}$. The frame rate is 30 frames $\mathrm{s}^{-1}$, including a GPSsynchronized timestamp. The magnetic ULF station utilizes a pair of EMI-BF4 magnetic induction coils recording ultralow frequency, $0.3-500 \mathrm{~Hz}$, which is located at the Lulin Observatory in the Taiwan central mountain ridge, as shown in Fig. 1 (Huang et al. 2011). The polarity, vertical current moment and time-integrated charge moment change (CMC) of TLEs and lightning are retrieved from the ULF signal. Further information can be found in Cummer (2003), Cummer et al. (2009), and Huang et al. (2012). 


\section{COORDINATED OBSERVATION TRIANGULATION FROM ISUAL AND THE GROUND CAMPAIGN}

\subsection{Convection System}

The events occurred on 9 August 2013 above a convection system in the mountainous area of Fujian, China. The system contained two convection cells, initiated at 13:00 LT and dissipated at 3:00 LT on the next day. The World Wide Lightning Location Network (WWLLN) data are shown in Fig. 2. The lightning activity during 11:00 - 14:00 UTC (19:00 - 22:00 LT) occurred in both convection cells A and B. After 14:00 UTC the lightning in cell A had already attenuated but that in cell B was still active. The four ground stations recorded 37 sprites over this thunderstorm system, and all of them were recorded by the PH and KM stations, as they were much closer to the convection system. The NCKU and TT stations failed to record any events due to local weather conditions and the long distance.

Seventeen of the 37 sprites were successfully observed with coordinated observation. The triangulation results indicate the first 14 events all occurred in cell $\mathrm{A}$, and the last 3 events occurred in cell B, as cell A had dissipated earlier. The last sprite event was also captured by ISUAL at 14:59:08 UTC, which is the first coordinated observation from space and ground in the world.

\subsection{Coordinated Observation from ISUAL and Ground Campaign}

For the coordinated campaign on 9 August 2013, because the distances between events and stations are $200-400 \mathrm{~km}$,

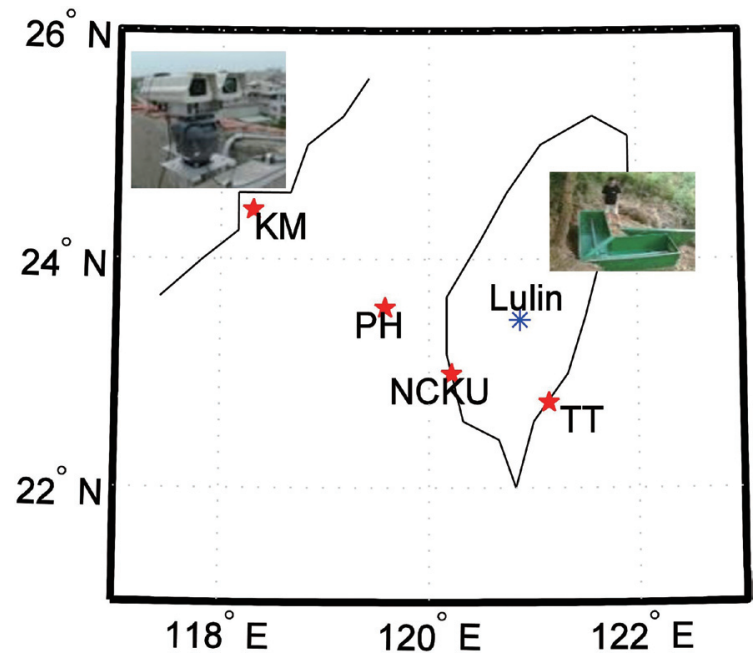

Fig. 1. The location of optical stations (red pentagram) and ULF station (blue star). (Color online only)
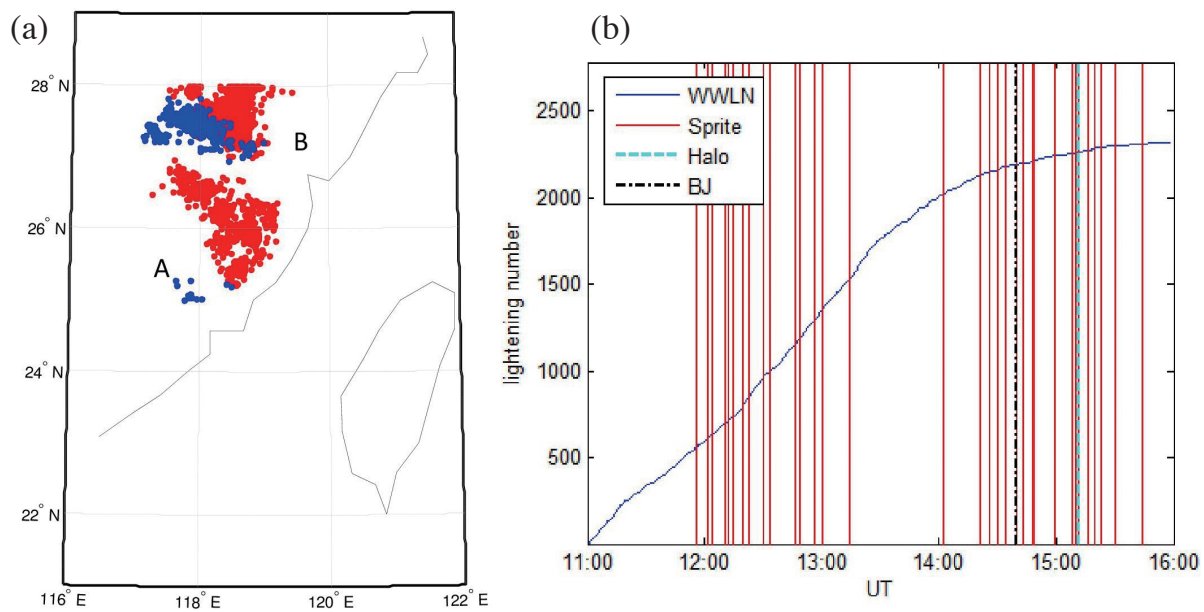

Fig. 2. (a) The lightning locating result from WWLLN shows there were 2 convection cells A and B. The red open squares are lightning occurred in 11:00 - 14:00 UTC and blue dots are lightning occurred in 14:00 - 16:00 UTC. (b) The lightning accumulating curve of the convection system is plotted as a blue curve, as the TLEs activity recorded from the ground campaign are marked in different vertical lines. (Color online only) 
the earth's curvature has to be taken into account. Following the procedures listed in the Appendix, if we know the latitude, longitude and altitude of the observation stations, and measure the azimuth and elevation angles of an illuminant event from each station, using Eqs. (A4) - (A15) in the Appendix, the geolocation and altitude of the event can then be determined. The azimuth and the elevation angles of the images were corrected according to the star field via UFO Analyzer, which is commercial software originally for analyzing the trajectory of meteors. The triangulation precision is determined mainly by the quality of the star field and pixel size. At $200-300 \mathrm{~km}$ from the ground station to event, the precision corresponding to one pixel is about $0.2 \mathrm{~km}$. The ISUAL geolocation error differs in azimuth and elevation direction, which will be discussed later.

The event images at 14:59:08 UTC recorded using the $\mathrm{PH}, \mathrm{KM}$, and the ISUAL Imager, are shown as Figs. 3a, b, and c, respectively. The SP and part of the AP data are also plotted in Figs. 3d and e, even though the sprite spectral signal was seriously contaminated by parent lightning and could not be discriminated. The weather at the PH site was fairly good; therefore, the stars could be identified automatically through the UFO Analyzer. On the other hand, the KM site was veiled by thin clouds, so only a few stars were discriminated manually. The ISUAL field of view was mostly covered by the Earth, and the imager degradation has become serious after a decade of operation. Therefore, only 2 stars could be manually identified for star field correction. The ISUAL image correction shows that the line of sight retrieved from quaternions is biased $0.206^{\circ}$ in azimuth and $-0.046^{\circ}$ in elevation, while the image also rotates $0.415^{\circ}$.

The geolocation and altitude of the sprite feature point was calculated by carefully dealing with the correction, marking the sprite feature point in all of the images (marked by arrows in Figs. 3a, b, and c), and substituting factors into the equations in the Appendix. The triangulation results are shown in Table 1 and Fig. 4. Point A is the map projection of the sprite feature point inferred from two ground stations, $\mathrm{KM}$ and $\mathrm{PH}$, regarded as the true sprite geographic location. Points $\mathrm{B}(\mathrm{C})$ are the results retrieved from ISUAL and the KM $(\mathrm{PH})$ station. The infrared enhanced cloud image overlaps the triangulation result, which shows that the event occurred at the edge of the coldest region of the infrared enhanced cloud image. The coldness of the infrared enhanced cloud image usually indicates deeper convective clouds in the upper troposphere. Both $\mathrm{B}$ and $\mathrm{C}$ are $\sim 6.8 \mathrm{~km}$ far away from $\mathrm{A}$. The circumradius of $\mathrm{A}, \mathrm{B}$ and $\mathrm{C}$ is $\sim 3.4 \mathrm{~km}$. The sprite feature point altitude determined by the $\mathrm{KM}$ and $\mathrm{PH}$ stations is 77.1 and $77.6 \mathrm{~km}$ respectively. The results are acceptable because the altitude difference of $0.5 \mathrm{~km}$ is comparable to the ground observation precision $\sim 0.2 \mathrm{~km}$ (see step 6 in Appendix.) The feature point altitudes determined by ISUAL and the KM $(\mathrm{PH})$ station are $75.7(75.3)$ and $76.1(75.3) \mathrm{km}$. These results are also acceptable because the altitude differences are comparable to the ISUAL precision $(\sim 2 \mathrm{~km})$.

The geolocation error induced by ISUAL could be estimated by assuming one pixel offset during measurement. While the events and ISUAL are $2500-3500 \mathrm{~km}$ apart, one pixel corresponds to a $2-3 \mathrm{~km}$ shift on the elevation (yaw axis) and the azimuthal direction (roll axis), and a $5-100 \mathrm{~km}$ shift along the line of sight (pitch axis). For the event at 14:59:08 UTC, it was $\sim 3000 \mathrm{~km}$ away from ISUAL; thus, the geolocation error for ISUAL would be $\sim 2.5 \mathrm{~km}$ on the altitude and along the limb of earth, and $\sim 8.5 \mathrm{~km}$ along the line of sight. Thus, the $\sim 6.8 \mathrm{~km}$ shift from the true location A to the results getting each ground station and ISUAL (B and $\mathrm{C}$ ) is acceptable.

Another TLEs coordinated observation from ISUAL and ground station (TT) was accomplished at 15:07:24 UTC on 17 July 2015 (not shown). Unfortunately, after decades of ISUAL Imager operation the image quality has seriously degraded, and thus, it is too poor to achieve the triangulation.

\subsection{Triangulation of Group Column Sprites}

Besides the ISUAL coordinated observation event mentioned above, three groups of columniform sprites were simultaneously recorded by the $\mathrm{KM}$ and $\mathrm{PH}$ stations. Although the appearance of each element in the group is similar, triangulation could still be achieved by following the procedures in the Appendix, step by step. The event geolocation at 12:56:03 UTC, shown in Fig. 5, demonstrates that there were six columns in a roughly circular distribution around a column sprite near the center. The parent lightning location was identified from the WWLLN data, which has a $6.8 \mathrm{~km}$ offset to the centric column of circular distributed sprite. The distribution pattern is very similar to Edgerton's famous Milk drop Coronet (Edgerton et al. 1987; Deegan et al. 2008). Moreover, the triangulation results from these events showed that the columns of sprites are longer and brighter near the parent lightning. The circular group of column sprites, occurring at the Eastern Mediterranean, was also reported by Vadislavsky et al. (2009). However, lacking of multiple site observations, they did not determine the exact relationship between the parent lightning and columniform sprites. A column sprite at the center of the circular distribution pattern was not reported either.

The images and map projection of the 13:00:33 UTC and 14:33:57 UTC events on 9 August 2013 are shown in Figs. 6 and 7. According to Figs. 6a, b and 7a, b, and following the arguments in the report by Vadislavsky et al. (2009), we may conclude that these sprites also had a circular distribution pattern and were centered directly above, or with a little offset to, the parent lightning. However, the triangulations show that the 13:00:33 UTC event had a parallel arrangement, and the 14:33:57 UTC event had a fan shape pattern, as shown in Figs. $6 \mathrm{c}$ and $7 \mathrm{c}$. Both parent lightning 


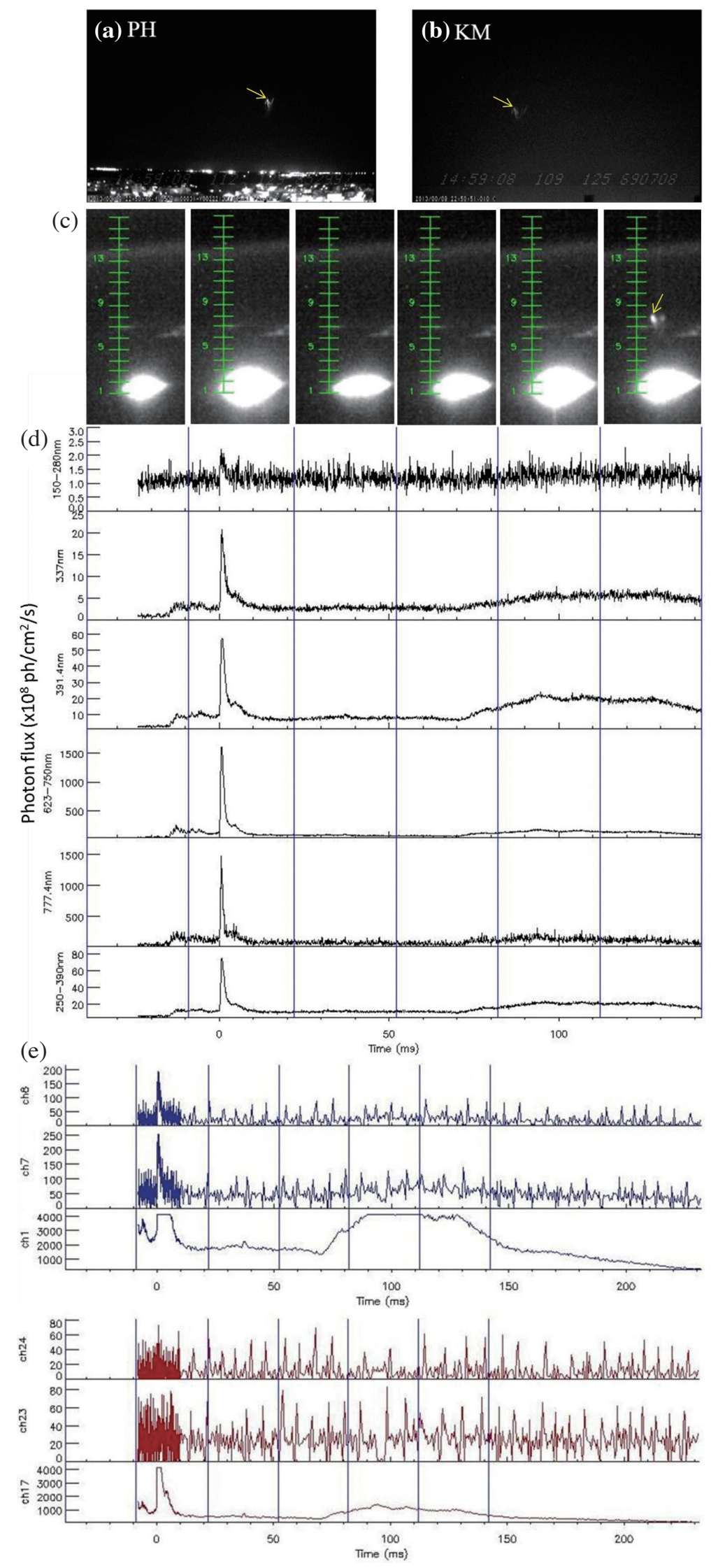

Fig. 3. The images of the simultaneous sprite recorded by (a) PH site, (b) KM site, and (c) ISUAL imager. The (d) ISUAL Spectrophotometer and (e) parts of Array Photometer data are also shown here. (Color online only) 
Table 1. The geolocations of the points $\mathrm{A}, \mathrm{B}$, and $\mathrm{C}$ are triangulation results from two ground stations and ISUAL. The point $\mathrm{D}$ is the geolocation by assuming that the parent lightning was at $15 \mathrm{~km}$ in height. For the point $\mathrm{E}$, the sprite is assumed to terminate at $90 \mathrm{~km}$ in height. The height is inferred from the geolocation and elevation angle, which are also listed in the table.

\begin{tabular}{cc|ccccc}
\hline & & Lat. $\left({ }^{\circ} \mathbf{N}\right)$ & Lon. $\left({ }^{\circ} \mathbf{E}\right)$ & Distance to A $(\mathbf{k m})$ & Height $(\mathbf{k m})$ & Height $(\mathbf{k m})$ \\
\hline A & KM-PH & 27.27 & 118.09 & N/A & 77.1 & 77.6 \\
B & ISUAL-KM & 27.21 & 118.12 & 6.82 & 75.4 & 76.1 \\
C & ISUAL-PH & 27.20 & 118.10 & 6.79 & 75.3 & 75.3 \\
D & ISUAL (cloud top) & 27.12 & 117.84 & 29.4 & 10 & N/A \\
E & ISUAL (TLE height) & 26.93 & 117.00 & 114.6 & 90 & N/A \\
\hline
\end{tabular}

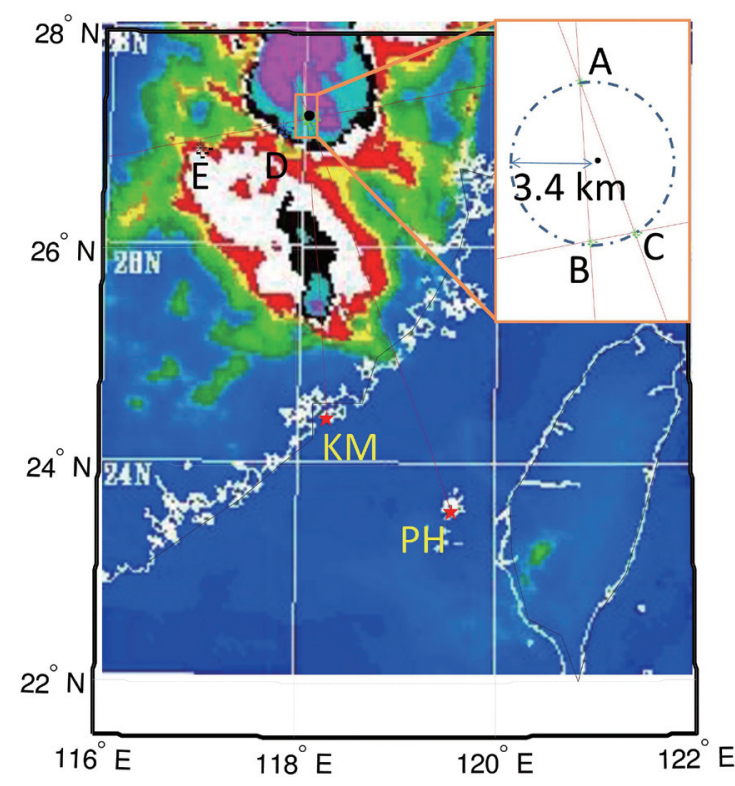

Fig. 4. The geolocation of triangulation result are plotted in infrared enhance cloud image. Points $\mathrm{A}, \mathrm{B}$, and $\mathrm{C}$ are triangulation geolocation result from the ground stations and ISUAL. Point $\mathrm{D}$ is the ISUAL result by assuming the parent lightning location in the image. Point $\mathrm{E}$ is the result from ISUAL by assuming the top of the sprite to be $90 \mathrm{~km}$. (Color online only)
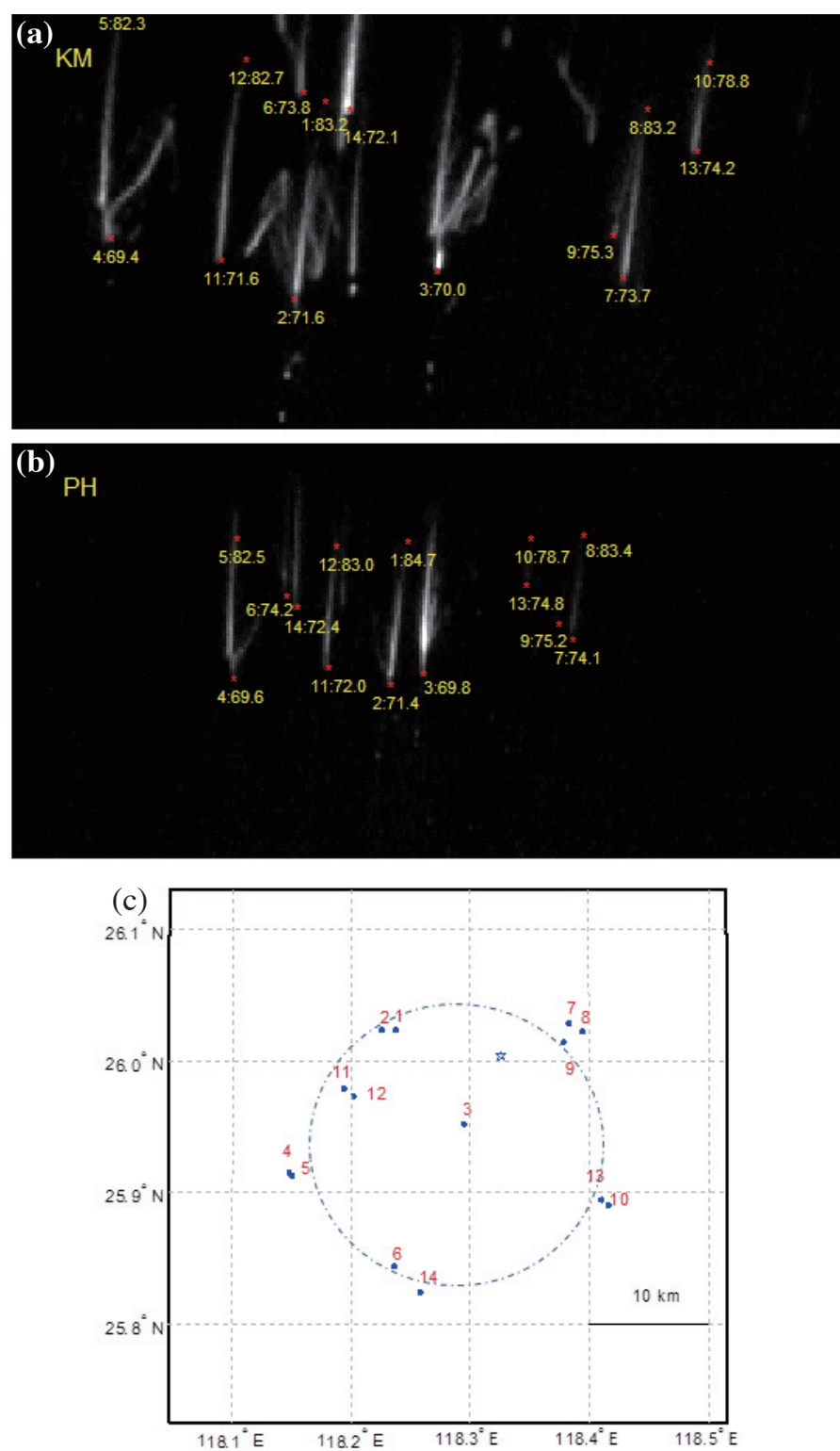

Fig. 5. The geolocation and retrieved height of event at 12:56:03 UTC recorded by KM and PH. The parent lightning geolocation from WWLLN is plotted in blue pentagram. (Color online only) 

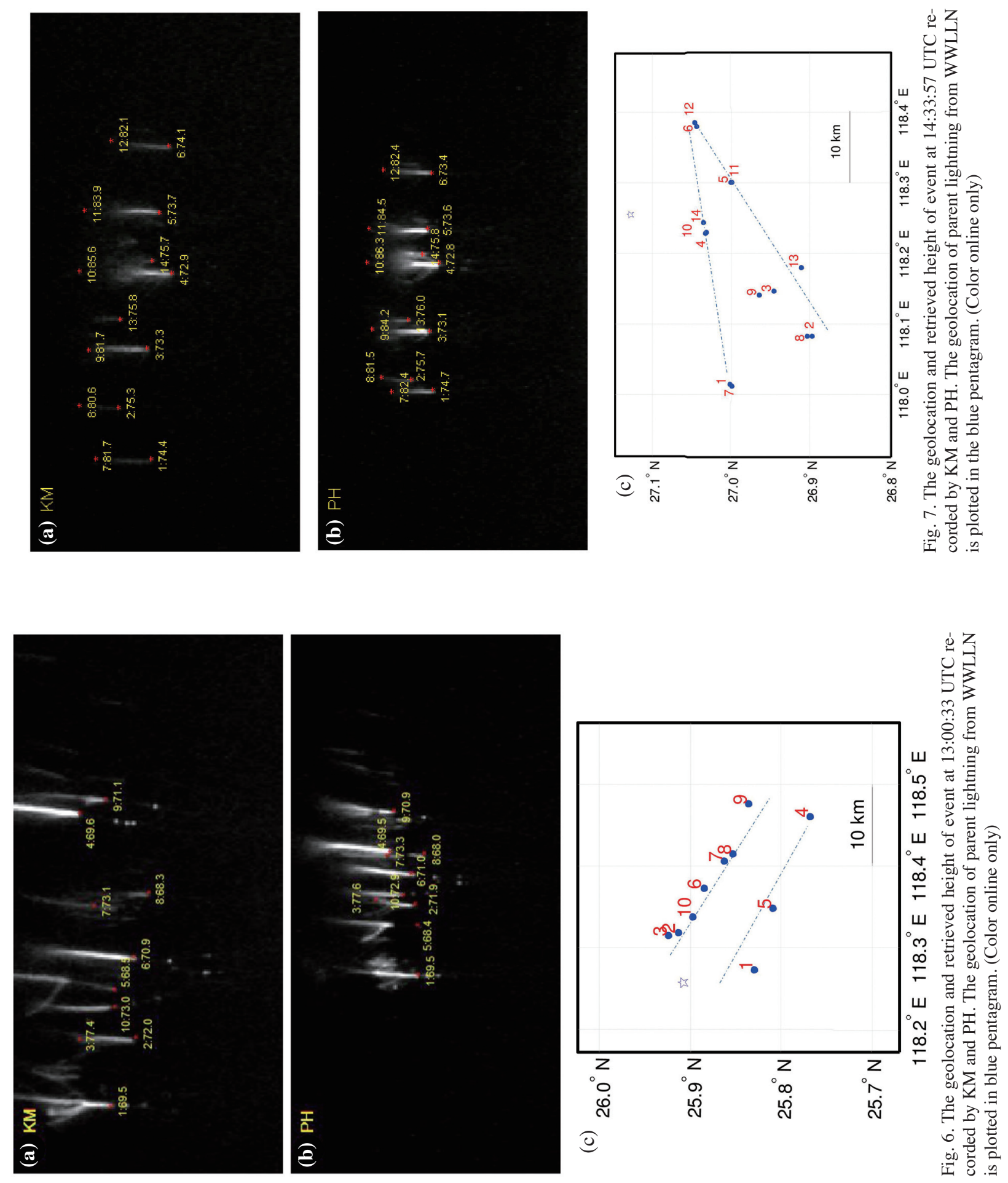
events, recorded by WWLLN, were located outside of the column distribution. These results show that the columniform sprite distribution patterns were diverse.

The event at 12:56:03 UTC had an average top altitude of $82.0 \pm 1.9 \mathrm{~km}$ and bottom altitude $72.3 \pm 2.2 \mathrm{~km}$. For the event at 13:00:33 UTC, we could only deduce the bottom mean altitude, $70.7 \pm 2.0 \mathrm{~km}$, because the top elements were out of the image; thus, there were no triangulation results. The average top and bottom altitudes for the event at 14:33:57 UTC were $82.6 \pm 1.8$ and $70.7 \pm 1.8 \mathrm{~km}$, respectively. As the width of each column in the images is about 1 - 2 pixels, considering that these events are at a distance of $\sim 300 \mathrm{~km}(400 \mathrm{~km})$ from KM (PH) site and image angle resolution is $0.04^{\circ}(\mathrm{H}) \times 0.045^{\circ}(\mathrm{V})$, it means that the sprite column diameter is $<0.5 \mathrm{~km}$.

\section{THE GEOLOCATION ACCURACY AND DETECTION EFFICIENCY OF ISUAL TLES}

Mapping the global distribution of TLEs is one of the objectives of the ISUAL payload (Chen et al. 2008). If the parent thundercloud is visible, the geolocation of an ISUAL TLE is deduced from the position of the center or the brightest pixel in the illuminated cloud top and the height is assumed to be $10 \mathrm{~km}$ (Smith et al. 1999). The sprite geolocation is obtained from the assumption of sprite maximum height $(90 \mathrm{~km})$ only when the parent thundercloud is invisible (Chen et al. 2004). We examined both of situations for the event at 14:59:08 UTC for comparison. Assuming the illuminated cloud top of its parent lightning is $10 \mathrm{~km}$ height and the sprite occurred above it, the geographic coordinate of the event could then be located at point $\mathrm{D}$, in Fig. 4, which is $\sim 29 \mathrm{~km}$ away from the true location A. For the sprite top to be $90 \mathrm{~km}$, the respective geolocation (point E) is $\sim 114 \mathrm{~km}$ apart from point $\mathrm{A}$. As mentioned above, since the true altitude of the sprite top is $77.4 \pm 0.3 \mathrm{~km}$, the large location error of point $\mathrm{E}$ does come from the assumption that the sprite top is $90 \mathrm{~km}$ in height.

Lu et al. (2013) pointed out that when the sprite is delayed for more than $40 \mathrm{~ms}$ after the parent lightning, the sprite location usually shifts more than $30 \mathrm{~km}$. The ULF signal of the simultaneous sprite producing lightning was recorded by the NCKU ULF station. From the ULF signal for the event at 14:59:08 UTC (not shown), the parent lightning was a $+\mathrm{CG}$ and the sprite occurred about $95 \mathrm{~ms}$ later, which was a long-delayed sprite. This means that the $\sim 30 \mathrm{~km}$ location error may be basically related to the shift in the parent lightning. However, WWLLN failed to detect the sprite producing lightning; therefore, the shift in the parent lightning cannot be examined through WWLLN data. The geolocation accuracy of ISUAL TLEs may be determined by the shift in parent lightning under the assumption that the illuminated cloud tops were at $10 \mathrm{~km}$ in height. The ULF signal also indicates that the peak current moment of the sprite produc- ing $+\mathrm{CG}$ is about $230 \mathrm{kA} \mathrm{km}$. The impulsive CMC (iCMC) integrates the $\mathrm{CMC}$ of the first $2 \mathrm{~ms}$ of the stroke (Cummer et al. 2013), which is about $210 \mathrm{C} \mathrm{km}$ for the sprite producing $+\mathrm{CG}$ of this event.

The quaternion of the FS-2 satellite is calculated via satellite sensors and onboard processing. The line of sight is then obtained through quaternion to locate the event. However, the coordinated observation shows that the quaternions are biased $0.206^{\circ}$ in azimuth, $-0.046^{\circ}$ in elevation, and the image also rotates $0.415^{\circ}$. While this shift would introduce an $8 \mathrm{~km}$ error to the true location, it is less than the ISUAL positioning error ( 29 or $114 \mathrm{~km}$ ). This error would not have any significant effect on the TLE global distribution reported by Chen et al. (2008) and Hsu et al. (2009), since the grid size of the distribution is $2.5^{\circ} \times 2.5^{\circ}$ (about $130-250 \mathrm{~km} \times$ $130-250 \mathrm{~km}$ ), which is much larger than the error caused by the quaternion.

Coordinated TLE observations from ISUAL and the ground campaign are for ISUAL geolocation accuracy validation and also available for investigating TLE detection efficiency. It is only $\sim 4$ minutes as the FOV of ISUAL passes through the effective range of ground observation near Taiwan. After more than a decade of coordinated observations, there are only two events that have been simultaneously recorded by ISUAL and the Taiwan ground campaign. By reviewing all of the records in the Taiwan ground campaign, we confirmed that only two events have occurred in the same time window. This indicates that ISUAL could record at least all events with iCMC $>210 \mathrm{C} \mathrm{km}$ under the ground observation sensitivity. This means that the TLE occurrence rate recorded by ISUAL (Chen et al. 2008; Hsu et al. 2009) is the same as the one determined by ground observations.

\section{CONCLUSION}

The ISUAL team has achieved the first coordinated observation from space and the ground. Spherical trigonometry and systematic procedures were employed for the triangulation of TLEs. In comparison with the ground campaign, the results indicate that geolocation accuracy is less than $7 \mathrm{~km}$ for the coordinated ISUAL and ground station observation. During the data analysis, it was found that the line of sight the ISUAL imager retrieved from quaternions has shifted $0.206^{\circ}$ in the azimuth direction and $-0.046^{\circ}$ in the elevation direction, while the image also rotates $0.415^{\circ}$. After researching the geolocation error and the detection efficiency of ISUAL TLEs, we conclude that the TLE global distribution reported before is reliable (Chen et al. 2008; Hsu et al. 2009), and no event with iCMC $>210 \mathrm{C} \mathrm{km}$ is missed by ISUAL, in comparison with the detect efficiency of ground observation.

The spatial distribution of individual columns in the group columniform sprite was performed accurately, which indicates one is circularly arranged with a column sprite at 
the center, and the others are arranged in parallel alignment or fan shape. This shows that the distribution patterns of columniform sprites are different from each other. The average base altitude, terminal altitude and diameter of each column of columniform sprites are $72.4 \pm 2.4,82.3 \pm 1.8$, and $<0.5 \mathrm{~km}$, respectively. Using these results, we can investigate how the parent lightning will affect the distribution, the brightness, and the length of each column in the near future.

Acknowledgements The authors wish to thank the World Wide Lightning Location Network (http://wwlln.net), a collaboration of over 50 universities and institutions, for providing the lightning location data used in this paper. This research was supported in part by Taiwan Ministry of Science and Technology (MOST) under Grant No. MOST 104-2111-M-006-005-MY2 and MOST 102-2112-M-006017-MY3.

\section{REFERENCES}

Boeck, W. L., O. H. Vaughan Jr., R. J. Blakeslee, B. Vonnegut, and M. Brook, 1998: The role of the space shuttle videotapes in the discovery of sprites, jets and elves. J. Atmos. Sol.-Terr. Phys., 60, 669-677, doi: 10.1016/ S1364-6826(98)00025-X. [Link]

Chang, S. C., C. L. Kuo, L. J. Lee, A. B. Chen, H. T. Su, R. R. Hsu, H. U. Frey, S. B. Mende, Y. Takahashi, and L. C. Lee, 2010: ISUAL far-ultraviolet events, elves, and lightning current. J. Geophys. Res., 115, A00E46, doi: 10.1029/2009JA014861. [Link]

Chen, A. B., C. L. Kuo, Y. J. Lee, H. T. Su, R. R. Hsu, J. L. Chern, H. U. Frey, S. B. Mende, Y. Takahashi, H. Fukunishi, Y. S. Chang, T. Y. Liu, and L. C. Lee, 2004: ISUAL calibration and optimal ground coverage for detecting transient luminous events. Eos Trans. AGU, Fall Meet. Suppl., Abstract AE31B-0164.

Chen, A. B., C. L. Kuo, Y. J. Lee, H. T. Su, R. R. Hsu, J. L. Chern, H. U. Frey, S. B. Mende, Y. Takahashi, H. Fukunishi, Y. S. Chang, T. Y. Liu, and L. C. Lee, 2008: Global distributions and occurrence rates of transient luminous events. J. Geophys. Res., 113, A08306, doi: 10.1029/2008JA013101. [Link]

Chern, J. L., R. R. Hsu, H. T. Su, S. B. Mende, H. Fukunishi, Y. Takahashi, and L. C. Lee, 2003: Global survey of upper atmospheric transient luminous events on the ROCSAT-2 satellite.J. Atmos. Sol.-Terr.Phys., 65, 647-659, doi: 10.1016/S1364-6826(02)00317-6. [Link]

Chou, J. K., C. L. Kuo, L. Y. Tsai, A. B. Chen, H. T. Su, R. R. Hsu, S. A. Cummer, J. Li, H. U. Frey, S. B. Mende, Y. Takahashi, and L. C. Lee, 2010: Gigantic jets with negative and positive polarity streamers. J. Geophys. Res., 115, A00E45, doi: 10.1029/2009JA014831. [Link]

Cummer, S. A., 2003: Current moment in sprite-producing lightning. J. Atmos. Sol.-Terr. Phys., 65, 499-508, doi: 10.1016/S1364-6826(02)00318-8. [Link]

Cummer, S. A., J. Li, F. Han, G. Lu, N. Jaugey, W. A. Lyons, and T. E. Nelson, 2009: Quantification of the troposphere-to-ionosphere charge transfer in a gigantic jet. Nat. Geosci., 2, 617-620, doi: 10.1038/ngeo607. [Link]

Cummer, S. A., W. A. Lyons, and M. A. Stanley, 2013: Three years of lightning impulse charge moment change measurements in the United States. J. Geophys. Res., 118, 5176-5189, doi: 10.1002/jgrd.50442. [Link]

Deegan, R. D., P. Brunet, and J. Eggers, 2008: Complexities of splashing. Nonlinearity, 21, doi: 10.1088/09517715/21/1/C01. [Link]

Edgerton, H. E., E. Jussim, and G. Kayafas, 1987: Stopping Time: The Photographs of Harold Edgerton, H. N. Abrams, New York, 18 pp.

Franz, R. C., R. J. Nemzek, and J. R. Winckler, 1990: Television image of a large upward electrical discharge above a thunderstorm system. Science, 249, 48-51, doi: 10.1126/science.249.4964.48. [Link]

Fukunishi, H., Y. Takahashi, M. Kubota, K. Sakanoi, U. S. Inan, and W. A. Lyons, 1996: Elves: Lightninginduced transient luminous events in the lower ionosphere. Geophys. Res. Lett., 23, 2157-2160, doi: 10.1029/96GL01979. [Link]

Hayakawa, M., T. Nakamura, Y. Hobara, and E. Williams, 2004: Observation of sprites over the Sea of Japan and conditions for lightning-induced sprites in winter. J. Geophys. Res., 109, A01312, doi: 10.1029/2003JA009905. [Link]

Hsu, R. R., H. T. Su, A. B. Chen, L. C. Lee, M. Asfur, C. Price, and Y. Yair, 2003: Transient luminous events in the vicinity of Taiwan. J. Atmos. Sol.-Terr. Phys., 65, 561-566, doi: 10.1016/S1364-6826(02)00320-6. [Link]

Hsu, R. R., A. B. Chen, C. L. Kuo, H. T. Su, H. Frey, S. Mende, Y. Takahashi, and L. C. Lee, 2009: On the global occurrence and impacts of transient luminous events (TLEs). AIP Conf. Proc., 1118, 99-107, doi: 10.1063/1.3137720. [Link]

Huang, S. M., C. L. Hsu, A. B. Chen, J. Li, L. J. Lee, G. L. Yang, Y. C. Wang, R. R. Hsu, and H. T. Su, 2011: Effects of notch-filtering on the ELF sferics and the physical parameters. Radio Sci., 46, RS5014, doi: 10.1029/2010RS004519. [Link]

Huang, S. M., R. R. Hsu, L. J. Lee, H. T. Su, C. L. Kuo, C. C. Wu, J. K. Chou, S. C. Chang, Y. J. Wu, and A. B. Chen, 2012: Optical and radio signatures of negative gigantic jets: Cases from Typhoon Lionrock (2010). J. Geophys. Res., 117, A08307, doi: 10.1029/2012JA017600. [Link]

Jehl, A., T. Farges, and E. Blanc, 2013: Color pictures of sprites from non-dedicated observation on board the 
International Space Station. J. Geophys. Res., 118, 454-461, doi: 10.1029/2012JA018144. [Link]

Kells, L. M., W. F. Kern, and J. R. Bland, 1951: Plane and Spherical Trigonometry, McGraw-Hill, New York, 183-203.

Kuo, C. L, R. R. Hsu, A. B. Chen, H. T. Su, L. C. Lee, S. B. Mende, H. U. Frey, H. Fukunishi, and Y. Takahashi, 2005: Electric fields and electron energies inferred from the ISUAL recorded sprites. Geophys. Res. Lett., 32, doi: 10.1029/2005GL023389. [Link]

Lee, L. J., A. B. Chen, S. C. Chang, C. L. Kuo, H. T. Su, R. R. Hsu, C. C. Wu, P. H. Lin, H. U. Frey, S. B. Mende, Y. Takahashi, and L. C. Lee, 2010: Controlling synoptic-scale factors for the distribution of transient luminous events. J. Geophys. Res., 115, A00E54, doi: 10.1029/2009JA014823. [Link]

Lee, L. J., S. M. Huang, J. K. Chou, C. L. Kuo, A. B. Chen, H. T. Su, R. R. Hsu, H. U. Frey, Y. Takahashi, and L. C. Lee, 2012: Characteristics and generation of secondary jets and secondary gigantic jets. J. Geophys. Res., 117, A06317, doi: 10.1029/2011JA017443. [Link]

Lu, G., S. A. Cummer, J. Li, L.Zigoneanu, W. A. Lyons, M. A. Stanley, W. Rison, P. R. Krehbiel, H. E. Edens, R. J. Thomas, W. H. Beasley, S. A. Weiss, R. J. Blakeslee, E. C. Bruning, D. R. MacGorman, T. C. Meyer, K. Palivec, T. Ashcraft, and T. Samaras, 2013: Coordinated observations of sprites and in-cloud lightning flash structure. J. Geophys. Res., 118, 6607-6632, doi: 10.1002/jgrd.50459. [Link]

Lyons, W. A., 1996: Sprite observations above the U.S. High Plains in relation to their parent thunderstorm systems. J. Geophys. Res., 101, 29641-29652, doi: 10.1029/96JD01866. [Link]

Pasko, V. P., M. A. Stanley, J. D. Mathews, U. S. Inan, and T. G. Wood, 2002: Electrical discharge from a thundercloud top to the lower ionosphere. Nature, 416, 152-154, doi: 10.1038/416152a. [Link]

Sentman, D. D., E. M. Wescott, D. L. Osborne, D. L. Hampton, and M. J. Heavner, 1995: Preliminary results from the Sprites94 aircraft campaign: 1. Red sprites. Geophys. Res. Lett., 22, 1205-1208, doi: 10.1029/95GL00583. [Link]

Smith, D. A., X. Shao, D. Holden, C. Rhodes, M. Brook, P. Krehbiel,M.Stanley, W. Rison, and R. Thomas, 1999: A distinct class of isolated intracloud lightning discharges and their associated radio emissions. J. Geophys. Res., 104, 4189-4212, doi: 10.1029/1998JD20045. [Link]

Stenbaek-Nielsen, H. C., D. R. Moudry, E. M. Wescott, D. D. Sentman, and F. T. S. Sabbas, 2000: Sprites and possible mesospheric effects. Geophys. Res. Lett., 27, 3829-3832, doi: 10.1029/2000GL003827 [Link]

Stenbaek-Nielsen, H. C., R. Haaland, M. G. McHarg, B. A. Hensley, and T. Kanmae, 2010: Sprite initiation altitude measured by triangulation. J. Geophys. Res., 115,
A00E12, doi: 10.1029/2009JA014543. [Link]

Su, H. T., R. R. Hsu, A. B. C. Chen, Y. J. Lee, and L. C. Lee, 2002: Observation of sprites over the Asian continent and over oceans around Taiwan. Geophys. Res. Lett., 29, 3-1-3-4, doi: 10.1029/2001GL013737. [Link]

Su, H. T., R. R. Hsu, A. B. Chen, Y. C. Wang, W. S. Hsiao, W. C. Lai, L. C. Lee, M. Sato, and H. Fukunishi, 2003: Gigantic jets between a thundercloud and the ionosphere. Nature, 423, 974-976, doi: 10.1038/nature01759. [Link]

Vadislavsky, E., Y. Yair, C. Erlick, C. Price, E. Greenberg, R. Yaniv, B. Ziv, N. Reicher, and A. Devir, 2009: Indication for circular organization of column sprite elements associated with eastern Mediterranean winter thunderstorms. J. Atmos. Sol.-Terr. Phys., 71, 18351839, doi: 10.1016/j.jastp.2009.07.001. [Link]

Van der Velde, O. A., W. A. Lyons, T. E. Nelson, S. A. Cummer, J. Li, and J. Bunnell, 2007: Analysis of the first gigantic jet recorded over continental North America. J. Geophys. Res., 112, D20104, doi: 10.1029/2007JD008575. [Link]

Wescott, E. M., D. Sentman, D. Osborne, D. Hampton, and M. Heavner, 1995: Preliminary results from the Sprites94 aircraft campaign: 2. Blue jets. Geophys. Res. Lett., 22, 1209-1212, doi: 10.1029/95GL00582 [Link]

Wescott, E. M., D. Sentman, M. J. Heavner, D. Hampton, W . A. Lyons, and T. Nelson, 1998: Observations of 'Columniform' sprites. J. Atmos. Sol.-Terr. Phys., 60, 733740, doi: 10.1016/S1364-6826(98)00029-7. [Link]

Yang, J., M. R. Yang, C. Liu, and G. L. Feng, 2013: Case studies of sprite-producing and non-sprite-producing summer thunderstorms. Adv. Atmos. Sci., 30, 17861808, doi: 10.1007/s00376-013-2120-5. [Link]

Yang, J., G. P. Lu, L. J. Lee, and G. L. Feng, 2015: Longdelayed bright dancing sprite with large horizontal displacement from its parent flash. J. Atmos. Terr. Phys., 129, doi: 10.1016/j.jastp.2015.04.001. [Link]

\section{APPENDIX: THE TRIANGULATION OF TLES}

Assuming the Earth is a perfect sphere, the following equations on spherical trigonometry (Kells et al. 1951) are employed for the triangulation of TLEs, and the angle definitions are shown in Fig. A1.

(1) Spherical cosine formulae:

$\cos A=-\cos B \cos E+\sin B \sin E \cos a$
$\cos B=-\cos A \cos E+\sin A \sin E \cos b$
$\cos E=-\cos B \cos A+\sin B \sin A \cos e$
$\cos a=\cos b \cos e+\sin b \sin e \cos A$
$\cos b=\cos a \cos e+\sin a \sin e \cos B$
$\cos e=\cos b \cos a+\sin b \sin a \cos E$ 
(2) Spherical sine formulae:

$$
\frac{\sin a}{\sin A}=\frac{\sin b}{\sin B}=\frac{\sin e}{\sin E}
$$

(3) The equations mentioned above also lead to the four-part formulae:

$\cos A \sin e=\cos a \sin b-\sin a \cos b \cos E$

$\cos B \sin e=\cos b \sin a-\sin b \cos a \cos E$

$\cos E \sin b=\cos e \sin b-\sin e \cos b \cos A$

$\cos B \sin b=\cos b \sin e-\sin b \cos e \cos A$

Let the latitude, longitude and altitude of observation stations $A$ and $B$ be $\left(\theta_{A}, \psi_{A}, h_{A}\right)$ and $\left(\theta_{B}, \psi_{B}, h_{B}\right)$, and the azimuthal angle and elevation angle of an illuminant event $\mathrm{E}$ from each station are $\left(\mathrm{Az}_{\mathrm{A}}, \alpha\right)$ and $\left(\mathrm{A} \mathrm{z}_{\mathrm{B}}, \beta\right) . \mathrm{A}^{\prime}, \mathrm{B}^{\prime}$, and $\mathrm{E}^{\prime}$ are the projection of $\mathrm{A}, \mathrm{B}$, and $\mathrm{E}$ on the spherical surface of the earth's radius as shown in Fig. A1a. The interior angle of $\triangle \mathrm{A}^{\prime} \mathrm{B}^{\prime} \mathrm{E}^{\prime}$ are defined as $\angle \mathrm{A}, \angle \mathrm{B}$, and $\angle \mathrm{E}$ and the geocentric angle corresponding to the sides of $\triangle \mathrm{A}^{\prime} \mathrm{B}^{\prime} \mathrm{E}^{\prime}$ are $\mathrm{a}=$ $\angle \mathrm{BOE}, \mathrm{b}=\angle \mathrm{AOE}$, and $\mathrm{e}=\angle \mathrm{AOB}$.

Using the following procedures, we can find out the latitude, longitude and altitude of the event $\mathrm{E},\left(\theta_{\mathrm{E}}, \psi_{\mathrm{E}}, \mathrm{h}_{\mathrm{E}}\right)$. Step1: The geocentric angle e from $\Delta \mathrm{N}^{\prime} \mathrm{A}^{\prime} \mathrm{B}^{\prime}$ is obtained from $\left(\psi_{\mathrm{A}}, \theta_{\mathrm{A}}\right)$ and $\left(\psi_{\mathrm{B}}, \theta_{\mathrm{B}}\right)$ via spherical cosine formulae, where $\mathrm{N}$ is North Pole and $\lambda$ is longitude difference. Notice that here the range of $\theta$ and $\psi$ are $0 \leq \theta \leq 180^{\circ}$ and $0 \leq \psi$ $<360^{\circ}$.

$\lambda=\psi_{\mathrm{B}}-\psi_{\mathrm{A}}$

$\cos \mathrm{e}=\cos \theta_{\mathrm{A}} \cos \theta_{\mathrm{B}}+\sin \theta_{\mathrm{A}} \sin \theta_{\mathrm{B}} \cos \lambda$

Step 2: The $\angle \mathrm{NA}^{\prime} \mathrm{B}^{\prime}$ and $\angle \mathrm{NB}^{\prime} \mathrm{A}^{\prime}$ are calculated by plugging $\left(\theta_{\mathrm{A}}, \psi_{\mathrm{A}}\right)$ and $\left(\theta_{\mathrm{B}}, \psi_{\mathrm{B}}\right)$ into spherical sine formulae and four-part formulae.

$\tan \angle \mathrm{NA}^{\prime} \mathrm{B}^{\prime}=\frac{\sin \lambda \sin \theta_{\mathrm{B}}}{\sin \theta_{\mathrm{A}} \cos \theta_{\mathrm{B}}-\sin \theta_{\mathrm{A}} \cos \theta_{\mathrm{B}} \cos \lambda}$

$\tan \angle \mathrm{NB}^{\prime} \mathrm{A}^{\prime}=\frac{\sin \lambda \sin \theta_{\mathrm{A}}}{\sin \theta_{\mathrm{B}} \cos \theta_{\mathrm{A}}-\sin \theta_{\mathrm{AB}} \cos \theta_{\mathrm{A}} \cos \lambda}$

$\angle \mathrm{A}$ and $\angle \mathrm{B}$ are obtained by subtracting azimuthal angles $\mathrm{A} \mathrm{z}_{\mathrm{A}}$ and $\mathrm{A} \mathrm{z}_{\mathrm{B}}$.

$\angle \mathrm{A}=\angle \mathrm{NA}^{\prime} \mathrm{B}^{\prime}-\mathrm{Az}_{\mathrm{A}}$

$\angle \mathrm{B}=\angle \mathrm{NB}^{\prime} \mathrm{A}^{\prime}+\mathrm{Az}_{\mathrm{B}}$
Notice that Eqs. (A7) and (A8) are valid only for the case shown in Fig. A1, if the $\mathrm{E}^{\prime}$ is located at the left side of the $\mathrm{A}^{\prime} \mathrm{B}^{\prime}$ curve, the relation will change.

Step 3: Then calculate $\angle \mathrm{E}$ in $\triangle \mathrm{A}^{\prime} \mathrm{B}^{\prime} \mathrm{E}^{\prime}$ from spherical cosine formulae:

$\cos \mathrm{E}=-\cos \mathrm{B} \cos \mathrm{A}+\sin \mathrm{B} \sin \mathrm{A} \cos \mathrm{e}$

At the results, the geocentric angle $\angle \mathrm{a}$ and $\angle \mathrm{b}$ are:

$\sin \mathrm{a}=\frac{\sin \mathrm{e}}{\sin \mathrm{E}} \sin \mathrm{A}$

$\sin b=\frac{\sin e}{\sin E} \sin B$

Step 4: The latitude of $E\left(\theta_{E}\right)$ is obtained from spherical cosine formulae in $\Delta \mathrm{NE}^{\prime} \mathrm{A}^{\prime}$,

$\cos \theta_{\mathrm{E}}=\cos \theta_{\mathrm{A}} \cos \mathrm{b}+\sin \theta_{\mathrm{A}} \sin \mathrm{b} \cos A z_{\mathrm{A}}$

Using the spherical sine formulae and four-part formulae, the longitude of $\mathrm{E}\left(\psi_{\mathrm{E}}\right)$ can be found from the longitude difference $\left(\psi_{\mathrm{E}}-\psi_{\mathrm{A}}\right)$ which can be expressed as

$\tan \left(\psi_{\mathrm{E}}-\psi_{\mathrm{A}}\right)=\frac{\sin \mathrm{e} \sin \mathrm{A}}{\sin \theta_{\mathrm{A}} \cos \mathrm{e}-\cos \theta_{\mathrm{A}} \sin \mathrm{e} \cos \mathrm{A}}$

Step 5: In $\triangle O E B, O E=h_{E}+R_{e}, O B=h_{B}+R_{e}$. $\left(R_{e}\right.$ is earth radius.). $\angle \mathrm{OBE}=90+\beta, \angle \mathrm{OEB}=90-\beta-$ a, the altitude of

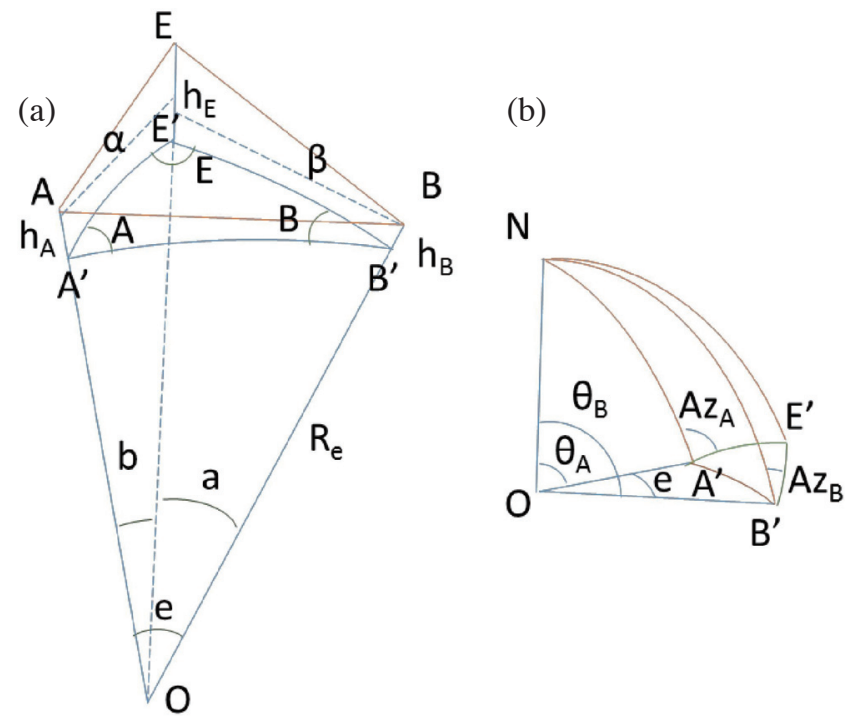

Fig. A1. The definition of angles and location of stations A, B, and event $\mathrm{E}$ on the earth. (Color online only) 
$E, h_{E}$, could be inferred from planar sine formulae

$h_{E}=\frac{O B}{\sin (90-\beta-a)} \sin (90+\beta)-R_{e}$

Use the same way, $h_{E}$ could also be estimated from $\triangle$ OEA,

$h_{E}=\frac{O A}{\sin (90-\alpha-b)} \sin (90+\alpha)-R_{e}$

Step 6: For ideal case, the altitude of event $h_{E}$ estimated from Eqs. (A14) and (A15) will be the same. However, for realistic case, it is hard to identify the same position point of the event on two images recorded from two different sites.
Therefore, the following optimization process is needed. (A) According to the sprite feature, identify the corresponding areas ( $\sim 5$ pixels $\times 5$ pixels $)$ on two images for triangulation. (B) Repeat the triangulation procedure from steps 1 to 5 for every pair of pixels which are selected from each area. (C) Estimate the altitude of event, $\mathrm{h}_{\mathrm{E}}$, from Eqs. (A14) and (A15) for every pair of pixel. (D) Figure out the pixel pair, which has a minimum difference between altitudes estimated in (C). (E) Finally, check that the minimum altitude difference must be comparable to the observation precision, say one pixel, and the error propagation in the calculation. For ground observation, the event is about $300 \mathrm{~km}$ away from to station, and then one pixel corresponds to about $0.2 \mathrm{~km}$. For the satellite observation the event is about $3000 \mathrm{~km}$ away from ISUAL, and one pixel corresponds to about $2 \mathrm{~km}$. 